\title{
Renaut, Galeran de Bretagne
}

\author{
Maria Colombo Timelli
}

\section{OpenEdition}

\section{Journals}

\section{Édition électronique}

URL : http://journals.openedition.org/studifrancesi/5525

DOI : 10.4000/studifrancesi.5525

ISSN : 2427-5856

\section{Éditeur}

Rosenberg \& Sellier

\section{Édition imprimée}

Date de publication : 1 septembre 2011

Pagination : 384

ISSN : 0039-2944

\section{Référence électronique}

Maria Colombo Timelli, « Renaut, Galeran de Bretagne », Studi Francesi [En ligne], 164 (LV | II) | 2011, mis en ligne le 30 novembre 2015, consulté le 08 janvier 2021. URL : http://journals.openedition.org/ studifrancesi/5525; DOI : https://doi.org/10.4000/studifrancesi.5525

Ce document a été généré automatiquement le 8 janvier 2021.

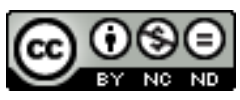

Studi Francesi è distribuita con Licenza Creative Commons Attribuzione - Non commerciale - Non opere derivate 4.0 Internazionale. 


\title{
Renaut, Galeran de Bretagne
}

\author{
Maria Colombo Timelli
}

\section{RÉFÉRENCE}

RENAUT, Galeran de Bretagne, Édition bilingue. Publication, traduction, présentation et notes par Jean DUFOURNET, Paris, Honoré Champion, 2009 («CCMA», 29), 603 pp.

1 Datant du début du XIII ${ }^{e}$ siècle, mais transmis par un manuscrit unique du $\mathrm{XV}^{\mathrm{e}}(\mathrm{BnF}$, fr. 24042), ce roman de quelque 8000 octosyllabes mérite bien d'être redécouvert, après les anciennes éditions d'Anatole Boucherie (1888, et non pas «Auguste Boucherie», comme il est dit pp. 41 et 54) et de Lucien Foulet (CFMA, 1926). Son auteur, qui ne doit être identifié ni avec Jean Renard, ni avec Renaut de Beaujeu, exploite habilement ses sources et ses modèles: les lais de Marie de France (Fresne et Milon), L'Escoufle et en partie Le Roman de la Rose de Jean Renart, dont il tire des noms - entre autres celui de la protagoniste, Fresne justement - et des motifs, qui pour rester reconnaissables n'en sont pas moins profondément transformés dans le sens d'une plus grande vraisemblance, sinon d'un plein «réalisme» comme on l'a prétendu pendant longtemps.

Dans son Introduction, Jean Dufournet fait le point du débat critique sur l'identité de l'auteur et surtout sur les questions littéraires: classement du roman, sources, caractéristiques de l'écriture de Renaut, en soulignant tout spécialement la co-présence dans Galeran de la tradition littéraire précédente et les effets de réel introduits par l'auteur, allant des descriptions d'objets à l'attention pour les aspects psychologiques, de la géographie du récit aux questions sociales liées à l'urbanisation et au rôle de l'argent. Un paragraphe à part est consacré au motif du double, qui fonde l'histoire (personnages, fonctions, objets se dédoublent constamment), jusqu'à la solution optimiste qui mène vers «l'unité de l'individu, du couple, de la famille, de la société» (p. 39).

3 Le manuscrit est rapidement présenté (pp. 41-42): acéphale, mal relié et lacunaire d'un certain nombre de vers, il reflète l'état de la langue du $\mathrm{xv}^{e}$ siècle; quelques observations 
sur la langue - notamment sur les traits phonétiques et morphologiques du Nord-Est trouvent place aux pp. 43-52.

4 L'édition du texte est accompagnée d'une traduction en prose claire et très agréable, qui respecte l'original sans tomber dans l'archaïsme (d'après mes sondages, c'est le même texte que J.D. a publié pour les traductions des «CFMA» en 1996). Il faut aussi souligner la richesse des notes (pp. 497-548: malheureusement, elles ne sont pas signalées dans le texte, ni dans la traduction), qui commentent certains faits de langue, les thèmes principaux, et des mots de civilisation qui risquent de demeurer opaques ou d'être interprétés approximativement par un lecteur non-spécialiste; elles contiennent aussi des renvois bibliographiques importants pour d'éventuels approfondissements.

5 Les Variantes (pp. 549-556) se rapportent aux éditions précédentes. Le Glossaire (pp. 557-585) ne constitue évidemment pas un double de la traduction, mais offre des correspondances et des gloses ponctuelles surtout là où la version en français moderne s'éloigne du texte médiéval. Suivent l'Index des noms propres (pp. 587-597), et un Index des mots étudiés [dans les notes] (pp. 599-601).

6 Une telle édition, œuvre d'un grand spécialiste, remet à la disposition des lecteurs un roman optimiste, un «centon» peut-être (p. 11), mais qui n'est pas dépourvu de qualités littéraires. 